\title{
Sintesis Tris(4-metoksifenil)tolilsilan dengan Teknik Reaksi Kopling Menggunakan Katalis Paladium Tersier Tributil Fosfin
}

\author{
Aldes Lesbani, Risfidian Mohadi, Eliza \\ Jurusan Kimia FMIPA Universitas Sriwijaya \\ J1. Raya Palembang Prabumulih Km. 32 Ogan Ilir 30662 Sumatera Selatan \\ Email: aldeslesbani@yahoo.com
}

\begin{abstract}
Abstrak
Telah disintesis senyawa tris(4-metoksifenil)tolilsilan (TMT) dengan teknik reaksi kopling menggunakan tolilsilan dan 4-iodida anisol yang dikatalis senyawa paladium. Reaksi dilakukan dalam kondisi inert dan suasana basa. Senyawa TMT hasil sintesis dikarakterisasi menggunakan kromatografi gas-spektrometri massa dan spektrometer ${ }^{1} \mathrm{H}$ dan ${ }^{13} \mathrm{C}$ NMR. Hasil penelitian menunjukkan bahwa senyawa TMT hasil sintesis memiliki rendemen sebesar $30 \%$. Pengukuran menggunakan kromatografi gas-spektrometri massa menghasilkan nilai $\mathrm{m} / \mathrm{z}$ sebesar 440 . Spektrum ${ }^{1} \mathrm{H}$ NMR menunjukkan lima puncak proton ekivalen dan spektrum ${ }^{13} \mathrm{C} \mathrm{NMR}$ menghasilkan sepuluh puncak karbon ekivalen. Hasil karakterisasi tersebut bersesuaian dengan struktur senyawa TMT hasil sintesis.
\end{abstract}

Kata kunci: tris(4-metoksifenil)tolilsilan, reaksi kopling, paladium

\begin{abstract}
The compound of tris(4-methoxyphenyl)tolylsilane (TMT) by coupling reaction technique using tolylsilane and 4-iodo anisole catalyzed by palladium compound has been synthesized. Reaction was carried out in inert condition and base medium. Compound TMT was characterized using gas chromatography-mass spectrometer, and ${ }^{1} \mathrm{H},{ }^{13} \mathrm{C}$ NMR spectrometer. The results showed that compound TMT has $30 \%$ yields. The measurement using gas chromatography-mass spectrometer gave $\mathrm{m} / \mathrm{z} 440$. ${ }^{1} \mathrm{H}$ NMR spectrum shows five proton equivalent peaks and ${ }^{13} \mathrm{C}$ NMR spectrum shows ten carbon equivalent peaks. All characterization data is appropriate with structure of compound TMT.
\end{abstract}

Keywords: tris(4-metoksifenil)tolilsilan, coupling reaction, palladium

\section{PENDAHULUAN}

Pengembangan sintesis organik untuk penemuan senyawa-senyawa baru yang berguna bagi kehidupan manusia terus dilakukan. Senyawa-senyawa baru tersebut dapat digunakan dalam bidang farmasi sebagai obat-obatan, dalam bidang pertanian sebagai pupuk atau pestidida serta dalam industri makanan dan minuman termasuk didalamnya industri parfum. Dalam rangka mencapai tujuan tersebut maka dilakukan pengembangan teknik sintesis yang bertujuan untuk memperpendek rute sintesis (Malleron et.al, 1997). Salah satu teknik sintesis senyawa organik yang dikembangkan dalam satu dekade terakhir ini adalah reaksi kopling (Tsuji, 2004). Reaksi kopling merupakan reaksi penggabungan rantai karbon-karbon atau bukan karbon dengan menggunakan katalis 
(Negishi, 2002). Katalis-katalis yang biasa digunakan dalam reaksi kopling merupakan katalis logam blok d pada umumnya termasuk senyawaan dan kompleks logam blok d. Akan tetapi ada juga beberapa unsur-unsur di blok s dan $\mathrm{p}$ yang dapat digunakan sebagai katalis dalam reaksi kopling (Hegedus, 2002).

Lesbani dkk telah melakukan reaksi kopling antara beberapa aril halida dengan senyawa organosilika menggunakan reaksi kopling dengan katalis paladium. Konsep ini telah diaplikasikan dalam sintesis senyawasenyawa baru yang mempunyai sifat fotoluminescence (Lesbani et.al, 2010) maupun sebagai pestisida yang bermanfaat bagi pertanian (Lesbani dkk, 2012). Beberapa jenis aril halida yang digunakan telah divariasi oleh Lesbani dkk dimana produk hasil reaksi kopling mempunyai variasi persentase produk yang beragam (Lesbani et.al, 2010). Disamping aril halida yang divariasikan, Lesbani dkk juga memvariasi organosilika yang digunakan dengan tujuan melihat kemampuan reaksi kopling yang dilakukan dengan katalis paladium tersebut. Produk hasil yang diperoleh memunjukkan bahwa reaksi kopling memiliki toleransi terhadap banyak aril halida dan organosilika dengan kemurnian yang tinggi (Lesbani Dan Mohadi, 2012). Akan tetapi variasi organosilika yang digunakan yakni fenilsilan, siklopentilsilan dan oktilsilan dan oktadesilsilan. Variasi organosilika yang lain yakni tolilsilan belum banyak dilaporkan sehingga akan dilaporkan dalam penelitian ini. Aril halida yang digunakan dalam penelitian ini yakni 4-iodida anisol yang telah digunakan pada beberapa reaksi dengan organosilika diatas. Keberhasilan proses reaksi kopling ditentukan dengan kemurnian produk yang dihasilkan dan persentase produk yang diperoleh.

\section{METODE PENELITIAN}

\section{Alat dan Bahan}

Alat-alat yang dipergunakan dalam penelitian ini meliputi seperangkat alat gelas kimia standar, peralatan sintesis meliputi labu Schlenk $50 \mathrm{~mL}$, syringe $5 \mathrm{~mL}, 10 \mathrm{~mL}$ dan 25 $\mathrm{mL}$, rotary evaporator, labu vakum dan pompa vakum. Peralatan analisis yang meliputi NMR Jeol $500 \mathrm{MHz}$ untuk ${ }^{1} \mathrm{H}$ dan $125 \mathrm{MHz}$ untuk ${ }^{13} \mathrm{C}$ dengan pelarut $\mathrm{CDCl}_{3}$, GC-MS Shimadzu serta melting point Fischer Jones.

Bahan-bahan yang dipergunakan dalam penelitian ini berkualitas analytical grade dan langsung dipergunakan tanpa pemurnian lebih lanjut yang meliputi tolilsilan $\mathrm{CH}_{3}\left(\mathrm{C}_{6} \mathrm{H}_{4}\right) \mathrm{SiH}_{3}$, 4-iodida anisol $\mathrm{CH}_{3} \mathrm{O}\left(\mathrm{C}_{6} \mathrm{H}_{4}\right) \mathrm{I}$, paladium tersier tributilfosfin $\left[\mathrm{Pd}\left(\mathrm{PtBu}_{3}\right)_{2}\right]$, gas argon, gas nitrogen tetrahidrofuran, 1,4diazabicyclo[2,2,2]oktan (DABCO), pelat TLC silika, etil asetat, diklorometan, heksana, serta akuades.

\section{Prosedur sintesis tris(4-metoksifenil) tolilsilan (TMT) dan karakterisasinya}

Prosedur sintesis dilakukan berdasarkan literatur Lesbani, et.al (2010) dengan adanya modifikasi yakni sebagai berikut: Sebanyak 0,05 mmol paladium tersier tributilfosfin, 5 mmol 1,4-diazabisiklo[2,2,2] oktan (DABCO), dimasukkan kedalam labu Schlenk ukuran 100 $\mathrm{mL}$ dan divakum selama 15 menit. Selanjutnya proses vakum dihentikan dan dimasukkan kedalam labu Schlenk tersebut $1 \mathrm{mmol}$ tolilsilan, $3 \mathrm{mmol} 4$-iodida anisol dan $3 \mathrm{~mL}$ tetrahidrofuran melalui syringe secara perlahan. Reaksi dilakukan pada suhu ruang tanpa pemanasan selama 3 hari. Reaksi dihentikan dengan cara penambahan $10 \mathrm{~mL}$ air kedalam campuran reaksi. Kemudian campuran dipindahkan kedalam corong pisah dan dilakukan ekstraksi menngunakan diklorometan sebanyak $15 \mathrm{~mL}$. Proses pemisahan produk dilakukan setelah didapat ekstrak pekat melalui teknik kromatografi cair. Proses rekristalisasi dilakukan menggunakan pelarut heksan. Produk reaksi kopling kemudian dikarakterisasi menggunakan GCMS, ${ }^{1} \mathrm{H},{ }^{13} \mathrm{C}$ NMR serta penentuan titik leleh.

\section{HASIL DAN PEMBAHASAN}

Reaksi kopling antara 4-iodida anisol dan tolilsilan menggunakan katalis palladium dengan konsep reaksi kopling pada penelitian ini disajikan pada Gambar 1.

Pada Gambar 1 terlihat bahwa penggunaan basa ditujukan untuk menarik tiga 


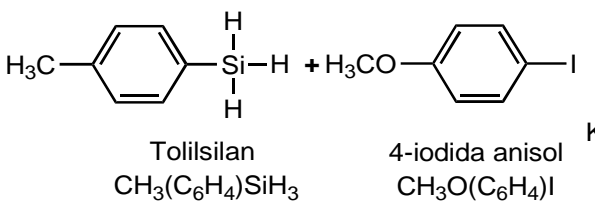

$\mathrm{CH}_{3}\left(\mathrm{C}_{6} \mathrm{H}_{4}\right) \mathrm{SiH}_{3}$

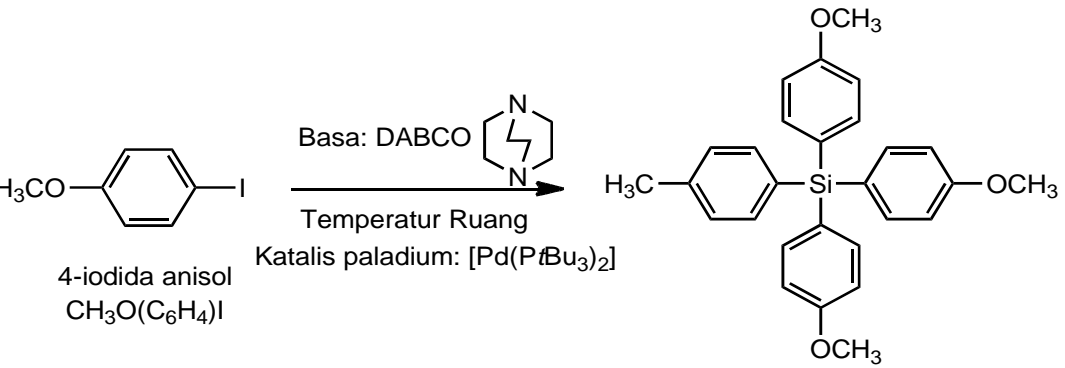

Tris(4-metoksofenil)tolilsilan, TMT

Gambar 1. Reaksi kopling antara tolilsilan dengan 4-iodida anisol membentuk senyawa TMT

hidrogen yang terdapat pada tolilsilan. Adapaun basa yang digunakan yakni 1,4diazabisiklo[2,2,2]oktan (DABCO) sebanyak 5 mmol untuk dapat mengakomodir seluruh hidrogen yang ada. Selanjutnya reaksi kopling dilakukan dengan substitusi 4-iodida anisol dengan tolilsilan yang dikatalis senyawa paladium dalam medium tetrahidrofuran. Selanjutnya pembentukan produk dimonitor dengan kromatografi lapis tipis dan kromatografi gas-spektrometer massa. Reaksi diperoleh tidak telalu besar akan tetapi dengan terbentuknya senyawa TMT menunjukkan reaksi dapat dilakukan dengan tolilsilan yang mempunyai gugus metil pada posisi para pada cincin aromatik. Hasil karakterisasi menggunakan kromatografi gas-spektrometer massa terhadap senyawa TMT disajikan pada Gambar 2.

Pada Gambar 2 terlihat bahwa senyawa TMT memiliki puncak ion molekul sebesar $\mathrm{m} / \mathrm{z}$ 440 dengan intensitas yang cukup tinggi. Nilai

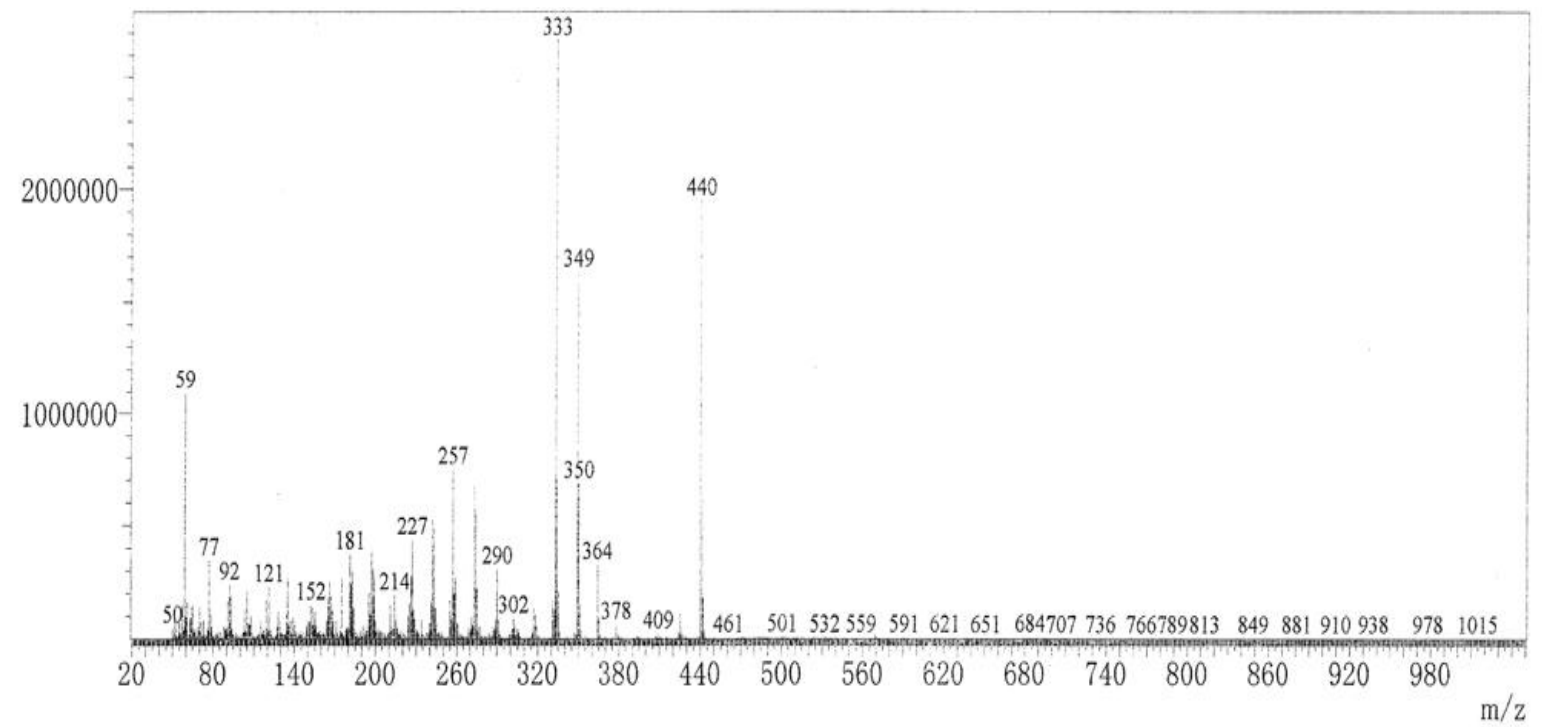

Gambar 2. Pola fragmentasi senyawa TMT

dihentikan apabila produk sudah terbentuk dan diekstraksi untuk selanjutnya dimurnikan dan dikarakterisasi. Hasil penelitian menunjukkan bahwa senyawa TMT berhasil disintesis dan dimurnikan dengan rendemen yang diperoleh sebanyak 30\%. Walaupun rendemen yang $\mathrm{m} / \mathrm{z}$ ini bersesuaian dengan struktur senyawa TMT seperti yang tersaji pada Gambar 1 . Intensitas tertinggi dimiliki oleh nilai $\mathrm{m} / z 333$. Nilai ini merujuk pada pola fragmentasi tiga gugus metoksi $\left(-\mathrm{OCH}_{3}\right)$ dan satu gugus metil ($\mathrm{CH}_{3}$ ) yang terikat pada senyawa TMT 


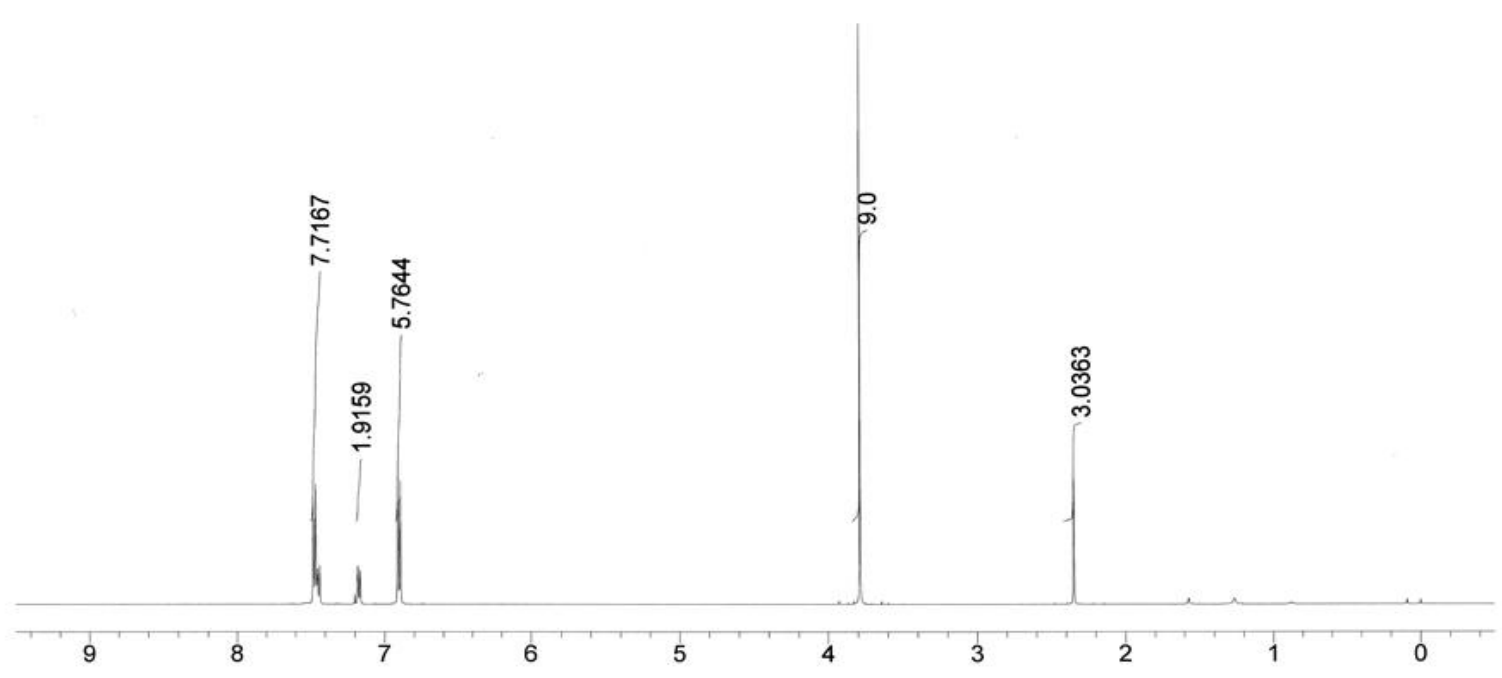

Gambar 3. Spektrum ${ }^{1} \mathrm{H}$ NMR senyawa TMT

(Solomons, 2008). Untuk selanjutnya dilakukan pengukuran menggunakan spektrometer ${ }^{1} \mathrm{H}$ NMR dengan frekuensi 500 MHz (Clayden et.al, 2008). Senyawa TMT dilarutkan dalam pelarut $\mathrm{CDCl}_{3}$. Spektra ${ }^{1} \mathrm{H}$ NMR senyawa TMT tersaji pada Gambar 3.

Spektra ${ }^{1} \mathrm{H}$ NMR pada Gambar 3 menunjukkan adanya lima puncak protonproton ekivalen pada senyawa TMT. Protonproton ekivalen tersebut yakni pada pergeseran kimia $\delta 2,35(\mathrm{~s}, 3 \mathrm{H}), 3,78(2,9 \mathrm{H}), 6,90(\mathrm{~d}, 6 \mathrm{H}$, $J=8,8 \mathrm{~Hz}), 7,17(\mathrm{~d}, 2 \mathrm{H}, J=7,6 \mathrm{~Hz})$, dan 7,46 (q, 8H, $J=8,2 \mathrm{~Hz}$ ). Penjumlahan total proton hasil integrasi dari lima puncak hasil pengukuran menggunakan ${ }^{1} \mathrm{H} \quad \mathrm{NMR}$ menghasilkan jumlah proton 28 buah proton. Bila dihitung secara teoritis jumlah proton pada senyawa TMT pada Gambar 1 yakni 28 buah proton dengan sebaran 9 proton metoksi ($\left.\mathrm{OCH}_{3}\right), 3$ proton metil $\left(-\mathrm{CH}_{3}\right), 12$ proton aromatik yang mengikat metoksi, dan 4 proton aromatik yang mengikat metil. Hasil pengukuran menggunakan ${ }^{1} \mathrm{H} \quad \mathrm{NMR}$

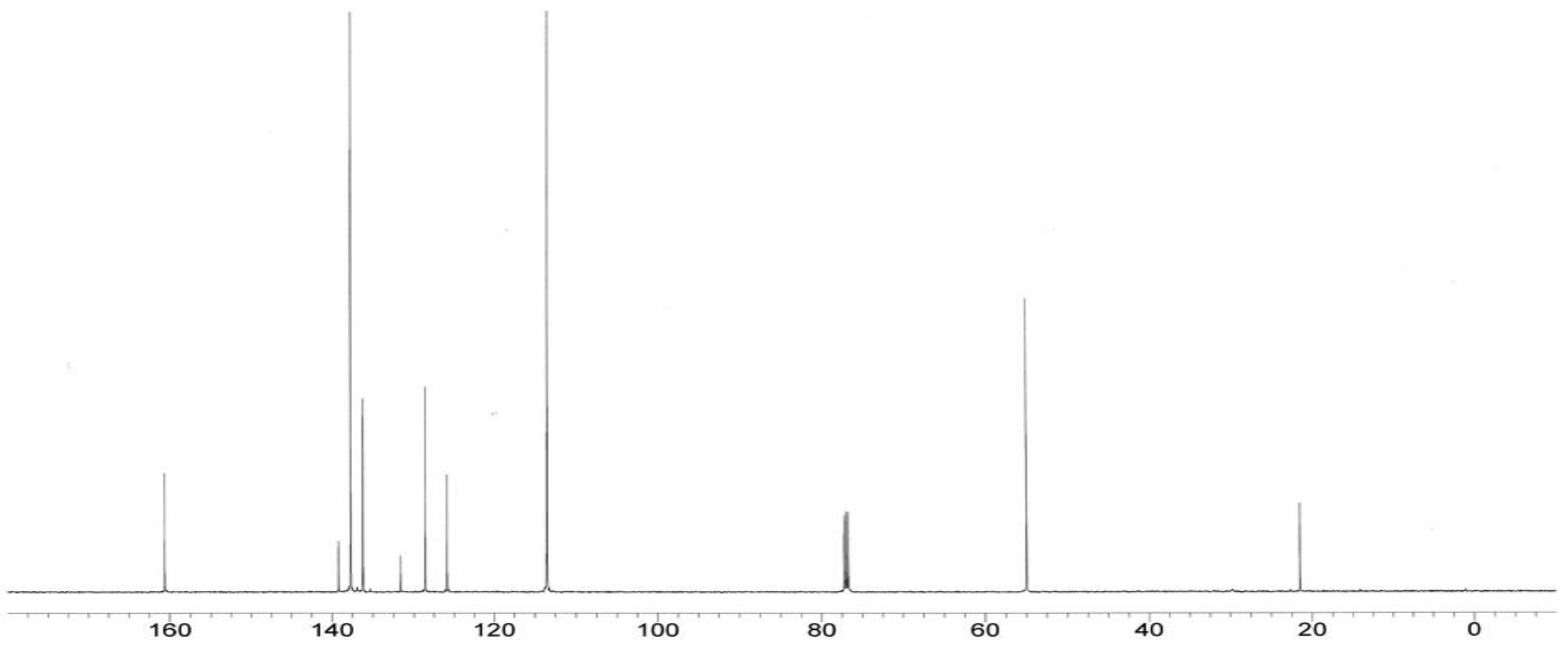

Gambar 4. Spektrum ${ }^{13} \mathrm{C}$ NMR senyawa TMT 
menunjukkan bahwa adanya korelasi antara data fragmentasi pada Gambar 1 dengan spektrum ${ }^{1} \mathrm{H}$ NMR. Untuk selanjutnya dilakukan pengukuran menggunakan ${ }^{13} \mathrm{C}$ NMR pada frekuensi $125 \mathrm{MHz}$ untuk memastikan keberhasilan reaksi pada Gambar 1. Spektra ${ }^{13} \mathrm{C}$ NMR senyawa TMT tersaji pada Gambar 4.

Spektrum ${ }^{13} \mathrm{C}$ NMR senyawa TMT menghasilkan 10 puncak karbon-karbon ekivalen. Karbon-karbon ekivalen tersebut yakni $\delta 21,5\left(\mathrm{CH}_{3}\right), 54,9\left(\mathrm{CH}_{3}\right), 113,5(\mathrm{CH})$, 125,9 (Cq), 128,6 (CH), 131,6 (Cq), 136,2 $(\mathrm{CH}), 137,7(\mathrm{CH}), 139,2(\mathrm{Cq})$, dan 160,6 (Cq). Hasil perhitungan secara teoritis terhadap jumlah karbon-karbon ekivalen pada senyawa TMT seperti yang tersaji pada Gambar 1 yakni 10 buah karbon-karbon ekivalen. Sebaran 10 karbon-karbon ekivalen tersebut yakni karbon metil $\left(-\mathrm{CH}_{3}\right)$ dari metoksi, karbon metil $\left(-\mathrm{CH}_{3}\right)$ dari gugus tolilsilan, empat karbon metin ($\mathrm{CH}$ ), dan empat karbon kuartener dari gugus aromatik. Kesepuluh karbon-karbon ekivalen ini tepat dengan struktur senyawa TMT. Dari keseluruhan hasil pengukuran dengan GC-MS, ${ }^{1} \mathrm{H}$ dan ${ }^{13} \mathrm{C}$ NMR jelas diketahui pasti bahwa senyawa (1) berhasil disintesis dengan teknik reaksi kopling menggunakan katalis paladium

\section{KESIMPULAN}

Senyawa tris(4-metoksifenil)tolilsilan (TMT) hasil sintesis memiliki kemurnian yang tinggi yang ditunjukkan oleh spektrum ${ }^{1} \mathrm{H}$ dan ${ }^{13} \mathrm{C}$ NMR yang tidak ditemukan puncak senyawa pengotor. Hasil karakterisasi menggunakan kromatografi gas-spektrometer massa serta ${ }^{1} \mathrm{H}$ dan ${ }^{13} \mathrm{C}$ NMR menunjukkan bahwa senyawa TMT telah berhasil disintesis dengan menggunakan reaksi kopling yang dikatalis senyawa paladium. Spektrum massa menunjukkan senyawa TMT memiliki bobot molekul dengan nilai $\mathrm{m} / \mathrm{z}$ sebesar 440 . Produk senyawa TMT yang dihasilkan sebesar $30 \%$.

\section{UCAPAN TERIMA KASIH}

Disampaikan kepada Prof. Hiroshi Nishihara, The University of Tokyo, Japan, dan staf teknisinya atas izin penggunaan alat dan bantuan pengukuran menggunakan NMR dan GC-MS.

\section{Daftar Pustaka}

Clayden, Greeves, Warren \& Wothers, 2008, Organic Chemistry, Oxford University Press, Oxford, UK.

Hegedus. L. S, 2002, Organometallics in Synthesis. Chichester: Wiley.

Lesbani. A, Kondo. H, Sato. J-ichi, Yamanoi. Y \& Nishihara. H. 2010. Facile Synthesis and Photoluminescent Poperties of Aryl-substituted Organisilanes; Chemical Communications, 46 : 7784-7786.

Lesbani. A, Kondo. H, Yamanoi. Y \& Hiroshi Nishihara. 2012 Sintesis Pestisida Flusilazol, Jurnal Kimia, FMIPA Universitas Udayana: 6, 1-7.

Lesbani. A, Mohadi. R. 2012. Tripel Arilasi Organosilika Primer Dengan Beberapa Aril Iodida Menggunakan Katalis Paladium, Chemistry Progress, Universitas Sam Ratulangi, 5,2: 66-69.

Lesbani. A, Yabusaki. Y, Kondo. H, Nakai. M, Yamanoi. Y \& Nishihara H. 2010. Integrated Palladium-catalyzed Arylation of the Heavier Group 14 Hydride; Chemistry A European Journal, 16: 13519-13527.

Malleron. J, Fiaud. J \& Legros. J, 1997, Handbook of Palladium-Catalyzed Organic Reactions, Academic Press, San Diego.

Negishi. E, 2002, Organopalladium Chemistry. New York: Wiley-Interscience.

Solomons. T.W.G, Fryhle. C.B, 2008, Organic Chemistry 9th Edition, John Wiley \& Sons, Inc, USA.

Tsuji. J, 2004, Palladium Reagents and Catalyst. Chichester: Wiley 